\title{
Caracterización textural con análisis de imagen: aplicación en cerámicas prehistóricas de Mallorca (1750-50 a.C.)
}

\author{
Textural characterization through image analysis: application to prehistoric pottery from \\ Mallorca (1750-50 BC)
}

Daniel Albero Santacreu ${ }^{a}$

\section{RESUMEN}

La caracterización de la textura de las pastas cerámicas resulta esencial para poder estudiar ciertas elecciones tecnológicas de los alfareros en el pasado. Este artículo aborda la importancia que tienen los análisis texturales en el estudio de la cerámica así como algunas de las técnicas y metodologías utilizadas para caracterizar la textura de las vasijas. Como estudio de caso se aporta la caracterización textural con análisis de imagen de 132 cerámicas de diversos yacimientos la Edad del Bronce y del Hierro de Mallorca. Gracias a la combinación de los resultados con diversos análisis estadísticos ha sido posible dividir el registro en grupos texturales relacionados con diversas elecciones tecnológicas. Un análisis diacrónico de estos grupos ha permitido conectarlos con cambios en las recetas y tradiciones tecnológicas a lo largo de la prehistoria balear.
Bronze and Iron Ages. Statistical analysis allowed us to classify the ceramic assemblage in various textural groups that are closely related to different technological choices. A diachronic analysis of these groups indicates that the textural differences found using this technique must be related to changes in paste recipes and technological traditions over the course of the prehistory of the Balearic Islands.

Palabras clave: Tecnología cerámica; Análisis textural; Digitalización de imágenes; Antiplásticos; Elección tecnológica; Arqueometría; Prehistoria; Protohistoria; Mediterráneo occidental.

Key words: Ceramic technology; Textural analysis; Image digitalization; Non-plastics; Technological choice; Archaeometry; Prehistory; Protohistory; West Mediterranean.

\section{INTRODUCCIÓN}

En términos generales la cerámica se compone de matriz arcillosa y de elementos no plásticos. En la matriz arcillosa, una fase más o menos continua, se sitúan componentes más gruesos como las inclusiones y, en algunos casos, los desgrasantes. Las primeras son partículas no plásticas que están de forma natural en las arcillas, mientras los segundos son antiplásticos añadidos intencional-

a Dpto. de Ciencias Históricas y Teoría de las Artes. Universidad de las Islas Baleares, Campus UIB. Ctra. Valldemossa km 7.5 s/n. 07122 Palma de Mallorca. Islas Baleares. España. Correo e.: d.albero@uib.es http://orcid.org/0000-0002-2438-8965

Recibido 5-VI-2015; aceptado 12-X-2015.

Copyright: (C) 2016 CSIC. Este es un artículo de acceso abierto distribuido bajo los términos de una licencia de uso y distribución Creative Commons Attribution (CC-by) España 3.0. 
mente por los alfareros ${ }^{1}$. Los estudios texturales se ocupan de ambos componentes de la fracción gruesa de la pasta, clasificándolos y dividiéndolos según su frecuencia, tamaño, ordenación y grado de esfericidad.

Muchos manuales centrados en el estudio de la cerámica (p. ej. Echallier 1984; Rice 1987; Gibson y Woods 1990; Orton et al. 1993; Velde y Druc 1999; Albero 2014a) señalan la trascendencia de determinar el tipo, la cantidad y el tamaño de los componentes de la fracción gruesa en los análisis de pastas efectuados en cerámicas arqueológicas. La textura de las vasijas se relaciona con el uso de materias primas arcillosas con granulometrías características. Además nos informa de las técnicas aplicadas por los alfareros en la preparación de las arcillas. Los análisis texturales nos aproximan al modo como gestionaron determinados recursos del entorno y al desarrollo de ciertas acciones técnicas a lo largo del espacio y el tiempo. Nos permiten abordar aspectos como la depuración de las arcillas o la adición de desgrasantes de naturaleza mineral o vegetal que alteran la granulometría de las materias primas. Todas estas acciones técnicas van cargadas de un fuerte significado social, pues responden a tradiciones tecnológicas, formas de hacer y estrategias de aprendizaje y de transmisión de conocimiento cuyo carácter contingente, propio de cada cultura, permite estructurar socialmente a las comunidades alfareras (Albero 2014a). Así mismo, gracias al estudio de la textura de las cerámicas podemos entender desde un punto de vista funcional otras fases del proceso de producción y el uso de la cerámica. Por ejemplo, las texturas gruesas suelen ser comunes en la confección de vasijas a mano de gran tamaño, ya que suelen requerir abundantes antiplásticos para consolidar la estructura de la pasta cuando se modela la pieza. Estos antiplásticos también evitan la aparición de fracturas durante las fases de secado y cocción, siendo indispensables para que la vasija conserve la forma. En este sentido, la textura influye en las propiedades físico-químicas de la pasta, las cualidades de la vasija y su comportamiento ante determinadas situaciones. El estudio de la textura, junto con otras variables como la tipología o el

\footnotetext{
${ }^{1}$ Este concepto designa a cualquier individuo, independientemente de su edad, género y estado físico-psíquico, cuyas actividades están vinculadas con la producción de cerámica.
}

análisis del contexto de uso y deposición, nos puede proporcionar información relevante para determinar si los alfareros promovieron intencionalmente una adaptación de la pasta a determinadas funciones. Gracias a él se pueden conocer las cualidades de la cerámica respecto a variables como la resistencia a la abrasión y al impacto o su efectividad calorífica (Bronitsky y Hamer 1986; Skibo y Schiffer 1987; Albero 2014a).

Finalmente, el análisis de la textura de la fracción gruesa tiene también un objetivo taxonómico al precisar diferencias o semejanzas granulométricas entre cerámicas con composición mineralógica análoga, clasificándolas en consecuencia. Las variaciones en el tipo, tamaño, forma y proporción de los antiplásticos nos pueden ayudar a agrupar cerámicas con un origen similar o realizadas con técnicas y materias primas muy parecidas. El estudio de texturas va a resultar especialmente eficiente y significativo en conjuntos cerámicos cuyas fábricas tengan texturas sensiblemente diferentes (Darvill y Timby 1982; Middleton et al. 1985; Gibson y Woods 1990).

Como puede apreciarse, el análisis textural constituye un aspecto importante en la caracterización de las pastas de las cerámicas arqueológicas por múltiples y diversos motivos. En este trabajo se exponen algunos de los métodos y estrategias tradicionalmente utilizadas para explicar después la aplicación del análisis de imagen a los estudios texturales y abordar la tecnología de las cerámicas arqueológicas. Esta es una técnica relativamente novedosa que ha tenido escasa implantación en nuestro país para analizar la fracción gruesa de las pastas. Se escoge como caso de estudio un conjunto de cerámicas de la Edad del Bronce y del Hierro de la isla de Mallorca.

\subsection{Análisis textural de pastas cerámicas: breve estado de la cuestión}

El análisis textural suele ser habitual y rutinario en la gestión de los conjuntos cerámicos recuperados en las excavaciones, recurriéndose a diversos procedimientos y estrategias. Ya desde los años 1980 diversos autores revisaron el potencial de los análisis texturales y reflexionaron sobre los procedimientos empleados. Hasta la reciente aparición del análisis de imagen, los pro- 
cedimientos de estudio de la textura de las pastas cerámicas han sido fundamentalmente dos. Uno de carácter cualitativo procede del campo de la sedimentología y se basa en el establecimiento de tablas comparativas (p. ej. Matthew et al. 1991; Barraclough 1992). El segundo, semi-cuantitativo, parte de un tedioso proceso de recuento y medida manual e individual de un número determinado de granos del fragmento cerámico. La rutina consiste en dividir la muestra en segmentos o cuadrantes para después estimar la cantidad de granos de diferentes tamaños presentes en cada uno. La cantidad de granos que deben ser medidos para dotar de significación y validez al análisis ha sido algo controvertida. El problema de este método radica en el tiempo requerido para la medición de la ingente cantidad de granos que suelen contener las cerámicas, especialmente si se considera un número elevado de ellos. Por eso muchos investigadores han optado por analizar sólo una muestra (Streeten 1982), triturar los fragmentos con el objetivo de extraer los granos para contarlos (Capel 1986) o dibujarlos para después medir su frecuencia (Hamilton 1977). Tradicionalmente se han considerado más significativas las mediciones que contaban con un número elevado de granos, especialmente a partir de 200 individuos. Sin embargo, los test han confirmado que con 50 granos o más se puede obtener una visión representativa de la textura de las cerámicas (Betts 1982; Darvill y Timby 1982, Kilmurry 1982; Middleton et al. 1985; Middleton et al. 1991).

Otra estrategia para caracterizar la fracción gruesa de la pasta consiste en establecer los rasgos texturales de cada mineral o tipo de roca de modo individual. Esta estrategia es altamente informativa, pero exige recurrir al microscopio petrográfico y a la preparación de láminas delgadas, ya que la lupa binocular resulta muy limitada para esta finalidad (Buxeda et al. 1991; Olaetxea 2000; Soltman 2001). Un inconveniente adicional es que el seccionamiento de la pieza durante la preparación de las láminas delgadas puede reducir los granos de mayor tamaño, especialmente si son mayores que las láminas delgadas, afectando a la representatividad de la sección (Orton et al. 1993). Otros autores (p. ej. Polvorinos et al. 2002; Albero 2011) optan por analizar la distribución del tamaño de los granos considerando los antiplásticos de la sección en conjunto, al margen de su composición mineralógica y distinguiendo sim- plemente los de tipo orgánico o vegetal y mineral. Para ello se emplea la lupa binocular normalmente sin demasiadas dificultades.

El importante desarrollo de la ciencia computacional y su aplicación generalizada al campo de la arqueología desde los 1990 han permitido la implementación de nuevas metodologías y rutinas analíticas más precisas y menos costosas para abordar el estudio de la cultura material. Gracias a ello los materiales y sus atributos se han caracterizado desde una óptica esencialmente cuantitativa, facilitando un registro más minucioso y completo de los artefactos, así como una comparación más precisa de los datos obtenidos. Algunos autores conscientes del potencial de este tipo de aproximaciones desarrollaron los primeros estudios texturales utilizando métodos computacionales (Middleton et al. 1985; Fieller 1991; Tucker 1991; Whitbread 1991). Sin embargo ha sido en los albores del siglo XXI cuando estas estrategias han cobrado importancia con la irrupción del análisis digital de imagen en el estudio de las texturas de materiales arqueológicos. Sus bases teórico-metodológicas consisten en acoplar un captador de imagen a un microscopio petrográfico o binocular y elaborar los resultados utilizando un software especializado de análisis de imagen.

Múltiples trabajos en el ámbito internacional aplican esta técnica al campo de la cerámica (p. ej. Velde y Druc 1999; Velde 2005; Sestier et al. 2003; Reedy 2006, 2008; Frahm et al. 2008; Carpenito et al. 2009; Livingood y Cordell 2009; Dal Sasso et al. 2014; Reedy et al. 2014; Sobott et al. 2014), pero sólo se han realizado algunos escasos aportes desde nuestro país (Gallart y Mata 1999; Polvorinos 2001; Polvorinos et al. 2002; Polvorinos et al. 2003; Polvorinos et al. 2005). Todos han demostrado sus ventajas al proporcionar de forma rápida y eficaz una descripción numérica completa referida, entre otros aspectos, al tamaño, la forma, el color y la posición de los objetos que se registran en la imagen. Los datos generados mediante esta técnica permiten una comparación estadística de las muestras que relaciona los rangos de tamaño y los porcentajes de antiplásticos presentes en las pastas. El cálculo de parámetros texturales cuantitativos -tales como porcentaje, área y perímetro de las partículas- deja de ser un mero complemento del estudio petrográfico tradicional para adquirir valor por sí mismo. Además 
de caracterizar texturalmente las pastas cerámicas, el análisis de imagen se muestra un método potencialmente eficaz para determinar si se ha utilizado más de una arcilla en la fabricación de una pieza o para detectar la presencia de desgrasantes y engobes a partir de particularidades en el tipo, tamaño y frecuencia de los antiplásticos (Velde 2005; Albero 2011; Albero et al. 2012).

El análisis automatizado de la textura de las pastas facilita datos más precisos para la reconstrucción de las tradiciones tecnológicas ligadas a la cerámica prehistórica, pero su aplicación no resulta válida per se. Como cualquier análisis textural, requiere que el investigador tenga conocimientos precisos acerca de la tecnología cerámica para poder determinar la significación de los resultados obtenidos. Nos referimos, por ejemplo, a la posibilidad de distinguir entre matriz arcillosa y antiplásticos, o entre antiplásticos orgánicos y minerales, una capacidad que difícilmente podrá ser automatizable.

En resumen, los procedimientos y estrategias para determinar la textura de las cerámicas en arqueología tienen ventajas e inconvenientes y requieren diferente grado de preparación de las muestras, de formación del investigador y de recursos materiales. Gran parte de los estudios desarrollan estos análisis con lámina delgada $\mathrm{y}$ microscopio petrográfico, mientras otros utilizan lupa binocular directamente sobre el propio fragmento. Los datos obtenidos pueden ser cualitativos, semi-cuantitativos o cuantitativos.

A continuación, evaluamos las posibilidades del análisis de imagen para el estudio de ciertas problemáticas ligadas a la producción y la tecnología cerámica de la Edad del Bronce y del Hierro de Mallorca.

\section{METODOLOGÍA Y SELECCIÓN DE MUESTRAS}

\subsection{Rutina analítica}

Se ha analizado la textura de 132 vasijas cerámicas observando directamente un corte fresco, a veces hecho mediante un disco, de cada fragmento. Esta estrategia ha permitido ampliar el número de cerámicas analizadas, reducir el tiempo de preparación de las muestras y evitar el coste de hacer láminas delgadas de todas ellas. Además, al utilizar el propio fragmento se ha podido trabajar con secciones de la cerámica de mayor tamaño, aumentando la representatividad del análisis. Para el análisis de imagen se ha adaptado un captador de imagen a un microscopio binocular de hasta 60x. Este último instrumento, a pesar de sus limitaciones, permite una primera sistematización de las pastas de las vasijas, de su estructura y textura (Cuomo Di Caprio 1985).

El examen óptico preliminar de las pastas se ha completado con un análisis cuantitativo de la textura de las piezas acoplando al microscopio binocular un software analizador de imagen y contemplando los antiplásticos minerales contenidos en las muestras como una sola fase. La identificación de la composición mineralógica de las piezas mediante análisis petrológico y difracción de rayos $\mathrm{X}$ evidencia que la amplia mayoría de los antiplásticos minerales detectados con este procedimiento son de naturaleza calcárea (fundamentalmente calcita espática). Otro tipo de minerales, como el cuarzo o los feldespatos, suelen ser muy minoritarios (Albero 2011; Albero y Mateu 2012; Albero et al. 2014). Estos minerales mayoritarios han podido ser identificados además mediante microscopio binocular (Albero 2014b). Gracias al análisis de imagen se ha obtenido una representación de la textura de la pasta asociable, básicamente, con las fases minerales mayoritarias detectadas en previos estudios arqueométricos. La estrategia de análisis ha limitado el estudio textural a una única fase mineral, excluyendo el análisis individualizado de las diferentes fases mineralógicas que conforman las fábricas. Estas se estudiaron de modo cualitativo mediante análisis petrológico en muchas de las muestras. Es decir, en el análisis textural que se presenta no es prioritario identificar los minerales contenidos en la pasta, sino averiguar la frecuencia, distribución y ordenación granulométrica de las partículas en conjunto, distinguiendo entre antiplásticos de origen mineral y vegetal. Este procedimiento resulta más rentable y se ajusta mejor a las necesidades analíticas de la muestra estudiada. Usando estas variables se pueden registrar determinados aspectos texturales de las pastas que luego pueden cruzarse con otros conjuntos de datos obtenidos de los análisis químicos, mineralógicos y petrológicos efectuados en estas mismas cerámicas. 
Un gran número de muestras cerámicas tiene fibras de materia vegetal añadidas intencionalmente a la pasta. El desgrasante vegetal es identificable en lámina delgada, mediante lupa binocular o incluso macroscópicamente por los negativos resultantes de su combustión. La medición de estos poros permite determinar el volumen original del desgrasante vegetal (Steponaitis 1984; Velde y Druc 1999). El área que ocupan en la sección de la cerámica nos aproxima a la cantidad de desgrasante orgánico presente en la pasta, así como a su morfología y dimensiones. Como se indicó, la lámina delgada resulta poco indicada para el estudio de este tipo de antiplásticos, ya que el tamaño de los desgrasantes puede superar la sección representada impidiendo observar, en muchos casos, la totalidad de los componentes. Así la presencia de este tipo de desgrasante en la pasta y sus características, se ha estimado trabajando a bajos aumentos con microscopio binocular.

Para el análisis de imagen se ha empleado una cámara digital Leica DFC-320 y un software de tratamiento de imagen Leica Qwin. La cámara se acopló a una microscopio binocular Heerbrugg Wild con lentes que comprenden entre 6 y $50 x$, y una lámpara alógena incorporada Volpi Intralux 5000 que favorece la obtención de micrografías en condiciones estandarizadas de luz. Como los fundamentos de la técnica de análisis de imagen ya han sido descritos por muchos investigadores (p. ej. Sonka et al. 1994; Gose et al. 1996; Barceló et al. 2001), nos limitaremos a describir el procedimiento empleado en este análisis. La rutina analítica consiste en tomar fotografías digitales calibradas de una sección limpia de la cerámica. Para la determinación porcentual de ciertos parámetros texturales y granulométricos se han empleado imágenes digitales con una resolución de 2000 ppp.

Una vez adquirida la imagen se han detectado los píxeles relacionados con los objetos que nos interesa medir. Los píxeles pueden corresponderse con diferentes combinaciones de escalas de grises o colores $R G B$. Como ciertos componentes de la cerámica (p. ej. desgrasantes, huellas en negativo, matriz fina) presentan colores de interferencia característicos, podemos seleccionar sólo los píxeles asociados a elementos relevantes para el análisis textural. En este estudio son los antiplásticos minerales. Este procedimiento permite individualizar los píxeles asociados a objetos como, por ejemplo, los desgrasantes calcáreos, de los relacionados con objetos no deseados, como la matriz fina. Para mejorar su detección en ocasiones se han alterado las imágenes a mano en el momento de su adquisición o bien una vez adquirida la imagen mediante operaciones matemáticas y aritméticas que modifican, principalmente, la luz y el color de los componentes de la misma. Algunos componentes por su alto contraste visual han sido fáciles de identificar y detectar, mientras otros han requerido un mayor tratamiento manual o automatizado de la imagen. Esto ha sucedido sobre todo cuando los objetos tenían una gama cromática parecida o no resaltaban respecto a la matriz en la que se insertaban (García del Amo 2000; Livingood y Cordell 2009). La medición de los poros dejados por la combustión de la materia orgánica no ha podido automatizarse. Cada poro identificado en la sección se ha registrado usando las herramientas de dibujo que incorpora el software de análisis de imagen.

Una vez detectados y editados los objetos se ha segmentado la imagen según un procedimiento basado en la lógica binaria que permite extraer una nueva imagen donde solo aparecen los píxeles asociados a los objetos seleccionados. Sobre esta imagen binaria, una vez individualizados los objetos por el software, se puede medir un amplio número de variables de modo automatizado. Como en otros estudios (Polvorinos et al. 2002), las variables consideradas son la superficie, el perímetro, la longitud, la anchura, la elongación y la redondez de cada grano mineral, así como de cada negativo atribuido a materia orgánica. El tamaño aparente de la partícula se ha estimado a partir del principio de Delesse que infiere el porcentaje de volumen a partir del área de la partícula. Según ese principio, el porcentaje que corresponde al área de una determinada fase en el plano de una imagen equivale al porcentaje en volumen de dicha fase. Los problemas derivan de las diferencias existentes en imágenes $2 \mathrm{D}$ y $3 \mathrm{D}$ entre medidas aparentes y reales (Zähle 1990).

La cantidad de antiplásticos se ha calculado a partir de su porcentaje en la pasta en términos de volumen siguiendo la fórmula especificada en García del Amo (2000). El valor de superficie específica de una fase se determina en función de un área de referencia que vendrá determinada por la resolución del píxel y el área de la totalidad de la imagen tratada. La resolución de 
cada píxel varía con los aumentos utilizados. En nuestro caso, las imágenes se han adquirido calibrando el analizador y el microscopio binocular utilizando $6 \mathrm{x}$ y obteniendo una resolución de 1 píxel $=5.51 \mu \mathrm{m}$. La utilización del microscopio binocular nos ha permitido trabajar a bajos aumentos, lo que favorece la digitalización de una área mayor de la sección de la cerámica incrementando el número de antiplásticos considerados en el análisis (Polvorinos et al. 2002). El área de la fase se obtiene directamente a través de las operaciones estándar del analizador de imagen en base al área de todos los objetos que conforman la fase contabilizando el número total de píxeles detectados en cada objeto. El valor de cada fase vendrá dada por la fórmula: $\% \mathrm{Vv}=$ píxeles (fase) x 100 /píxeles (totales)

La granulometría de los antiplásticos es una variable de gran importancia en los estudios texturales de cerámicas. La estimación de la distribución unimodal, bimodal o polimodal de los tamaños de grano existentes en las pastas se considera un método utilizable, a veces, para identificar la adición de desgrasantes (Quinn 2013). Esa determinación exige combinar este parámetro con variables como la angulosidad y la cantidad de desgrasante presente en la pasta (Maggetti 1982; Gibson y Woods 1990; Velde 2005). Ya se ha señalado la gran controversia que existe en los estudios de texturas sobre la cantidad de granos que deben ser medidos para que el resultado posea significación. En nuestro caso, al disponer de medios automatizados, por regla general, se detectan todos los granos de la imagen y, por tanto, se recuenta el máximo número de granos posible en cada muestra. La aplicación de esta técnica ha proporcionado tablas con una cantidad ingente de individuos, obligando a su agrupación en una serie de intervalos de tamaño que facilitan la presentación y el tratamiento adecuado de los datos. La gran dispersión de los individuos ha aconsejado aplicar una escala logarítmica entre 50 y $4.000 \mu \mathrm{m}$ con el fin de representarlos a todos.

Según el procedimiento aplicado en otros estudios (Middleton et al. 1985), se han excluido los granos inferiores a $50 \mu \mathrm{m}$ de diámetro relacionados con limos muy finos. La variable "longitud máxima" registra la dimensión de los granos que componen la fracción gruesa. Es una variable usada tradicionalmente, tanto en los estudios de lámina delgada como en las clasificaciones que utilizan tablas comparativas. De este modo se favorece la comparación con los resultados obtenidos en otras clasificaciones texturales. Es decir, en cada imagen se han tenido en cuenta los granos de más $50 \mu \mathrm{m}$ de longitud. Para establecer los desgrasantes adscritos a cada intervalo de tamaño, se ha calculado el porcentaje de área que ocupan respecto al total de la fase. El cálculo de volumen que ocupan en la matriz las inclusiones de cada intervalo (Vi) de tamaño viene determinado por la fórmula: $\% \mathrm{Vi}=$ píxeles (intervalo) x 100 /píxeles (fase).

Al final del proceso obtenemos un diagrama de dispersión, un histograma y una imagen mapeada en la que aparecen los antiplásticos minerales de la pasta clasificados en función del intervalo de tamaño al que se adscriben. Finalmente, para comparar con más facilidad la textura de las distintas muestras hemos agrupado los intervalos establecidos anteriormente en tres categorías: grano fino $<0,3 \mathrm{~mm}$; grano medio $0,3-0,8 \mathrm{~mm}$; grano grueso $>0,8 \mathrm{~mm}$.

\subsection{Selección de muestras}

Las 132 formas cerámicas muestreadas proceden de cuatro yacimientos mallorquines cuyos niveles arqueológicos, en conjunto, abarcan desde la Edad del Bronce Antiguo (1750 a.C.) hasta prácticamente el cambio de era (50 a.C.). El examen macroscópico preliminar de las pastas sugiere importantes diferencias texturales que deben ser estimadas con mayor precisión. Se han seleccionado 11 formas cerámicas del Navetiforme I del poblado de Closos de Can Gaià. Proceden de niveles relacionados con la fase previa a la construcción del navetiforme en el Bronce Antiguo (c. 1750 a.C.), de la primera fase de uso de la estructura en el Bronce Medio tras su construcción en el c. 1650-1500 a.C. y de su fase final de uso alrededor del c. 850/800 a.C. (Javaloyas et al. 2007). Del yacimiento turriforme escalonado de Son Ferrer (Calvo et al. 2014) se han analizado 37 cerámicas de niveles de la Edad del Bronce (1400-1000 a.C.), de la Edad del Hierro Inicial (Talayótico, 850/750-550 a.C.) y, especialmente, de la Edad del Hierro Final (Postalayótico, 500-50 a.C.). De la Torre I de Puig de Sa Morisca se han seleccionado 48 cerámicas. Proceden de niveles 
de la Edad del Bronce Final (c. 1200-900 a.C.), unas cuantas de la Edad del Hierro Inicial (c. 750 a.C.) y la mayoría de la primera fase de la Edad del Hierro Final (Postalayótico I, siglo IV a.C.) (Guerrero et al. 2002). Finalmente, se han analizado 36 vasijas del Turó de les Abelles, un asentamiento próximo al anterior, iniciado a finales del siglo III a.C., ocupado durante la segunda fase de la Edad del Hierro Final (Postalayótico II) y abandonado en la primera mitad del siglo I a.C. (Camps y Vallespir 1998).

La estrategia diacrónica del muestreo con la selección de muestras de amplia distribución cronológica iba destinada a establecer los cambios en las elecciones tecnológicas adoptadas por los alfareros de la prehistoria mallorquina. Como resultado se han analizado 4 vasijas de la Edad del Bronce Antiguo, 20 vasijas del Bronce Medio y Final (Bronce naviforme), 10 vasijas de la Edad del Hierro Inicial (Talayótico), 42 de la primera fase de la Edad del Hierro Final (Postalayótico I) y 56 de la segunda fase de la Edad del Hierro Final (Postalayótico II).

\section{RESULTADOS}

Los resúmenes descriptivos obtenidos del análisis textural evidencian una gran variabilidad en las pastas dependiendo de la cantidad de fase mineral, del tamaño de los granos y del porcentaje de materia orgánica presente en las muestras (Tab. 1). Hay numerosas piezas que apenas tienen desgrasante vegetal, mientras otras lo tienen en abundancia. Lo mismo ocurre con las inclusiones minerales. La gran variabilidad de texturas observadas en el registro sugiere establecer di- versos grupos texturales (GT) en el conjunto de datos para favorecer su lectura e interpretación arqueológica. Estos GT permitirán, posteriormente, obtener información sobre ciertos parámetros de la cerámica que son importantes para abordar cuestiones relacionadas, principalmente, con la tecnología y la funcionalidad de las piezas.

Los GT se han definido mediante un análisis multivariante de conglomerados jerárquicos utilizando agrupación al centroide y distancia euclidiana al cuadrado. El criterio de la abundancia es uno de los que suelen manejarse en los estudios texturales para determinar la adición de desgrasante a las piezas, aspecto con especial relevancia tecnológica y funcional (Gherdán y Kovath 2009: 273). Cuanto más mineral tiene una pieza más probabilidades hay de que se haya añadido de modo artificial. Por ello se ha creído conveniente que el análisis de conglomerados fijara prioritariamente las aglomeraciones a partir de la cantidad de desgrasante mineral de las pastas. Para dar mayor peso a esta variable se han multiplicado x10 sus valores. De este modo, el clúster considerará en segundo término el tamaño del desgrasante y la cantidad de materia vegetal para definir los distintos grupos.

Este procedimiento pretende evitar agrupaciones, basadas fundamentalmente en el tamaño de los antiplásticos, que comprendan piezas con pocas y muchas inclusiones o desgrasantes pero cuyo tamaño mayoritario sea parecido. La razón estriba en que no se consideran útiles para definir una clasificación de GT eficaz en posteriores aplicaciones relativas a la tecnología y la potencialidad morfológica o funcionalidad de las piezas. Otro motivo para considerar el desgrasante vegetal en un segundo nivel es la alta variabilidad y dispersión observada en los valores de este ma-

\begin{tabular}{|l|c|c|c|c|c|c|}
\hline & $\mathrm{N}$ & Mínimo & Máximo & Media & Desv. típ. & CV \\
\hline$\%$ Mineral & 132 & 0,5 & 28,0 & 8,9 & 6,6 & 0,74 \\
\hline$\%$ Materia orgánica & 132 & 0 & 21,1 & 5,5 & 5,1 & 0,92 \\
\hline$\%<300 \mu \mathrm{m}$ & 132 & 8,1 & 92,4 & 31,1 & 17,6 & 0,56 \\
\hline$\% 300-800 \mu \mathrm{m}$ & 132 & 7,6 & 83,0 & 48,8 & 14,8 & 0,30 \\
\hline$\%>800 \mu \mathrm{m}$ & 132 & 0 & 68,7 & 20,0 & 19,5 & 0,97 \\
\hline
\end{tabular}

Tab. 1. Estadísticos descriptivos de las variables texturales estudiadas con análisis de imagen $(\mathrm{CV}=$ coeficiente de variación de Pearson) en cerámicas de cuatro yacimientos mallorquines. 
terial $(\mathrm{C} . \mathrm{V} .=0,92)$, así como su escasa correlación con la cantidad de antiplásticos de origen mineral (correlación $r$ Pearson $=-0,523$ ). Ello daba lugar a multitud de agrupaciones donde se asimilaban piezas con cantidades muy divergentes de fase mineral, dificultando el establecimiento de GT que tuvieran el carácter comprensible, práctico y comunicador que debe perseguir cualquier propuesta clasificatoria. Como resultado en cada GT se han introducido subgrupos a partir de agrupaciones jerárquicas en función de la cantidad de materia orgánica identificada en las muestras. Las agrupaciones resultantes son representativas de las texturas del conjunto analizado y constituyen un marco adecuado de referencia para futuras clasificaciones de la textura de pastas cerámicas prehistóricas de las Islas Baleares. Se ordenan principalmente atendiendo a la cantidad de desgrasante mineral y el tamaño que predomina en la muestra $y$, en segundo término, a la cantidad de materia orgánica.

Tras el análisis estadístico las muestras cerámicas se han clasificado en cuatro grandes GT según la cantidad de antiplástico mineral y su tamaño. En el dendograma se observan además variantes en algunos grupos que responden a la cantidad de poros asociados a la materia orgánica (Fig. 1). Las muestras de textura gruesa se agrupan arriba y las de textura fina abajo. Los atributos de los grupos obtenidos en el dendrograma se ven claramente en un gráfico de dispersión que representa el porcentaje de antiplásticos minerales en la pasta respecto al porcentaje de granos de más de $300 \mu \mathrm{m}$ (Fig. 2A). Estas diferencias texturales se constatan también en las curvas granulométricas (Fig. 2B). Las curvas de los GT-A y B son muy semejantes y reflejan una coincidencia del tamaño de grano. Sin embargo difieren en la /cantidad de antiplásticos minerales presentes en las muestras. Las curvas de ambos grupos se diferencian con claridad de las correspondientes a los GT-C y D. Se confirma así que las agrupaciones logradas en el análisis de conglomerados jerárquicos responden básicamente a la cantidad de desgrasante mineral y a su tamaño de partícula. El clúster ha constatado el empleo de pastas gruesas con abundantes antiplásticos minerales (GT-A, GT-B2 y GT-D) y escasa materia orgánica, así como de otras de carácter más fino con más importancia del desgrasante vegetal que mineral, siendo este de granulometría variable (GT-B1 y GT-C). Esta-

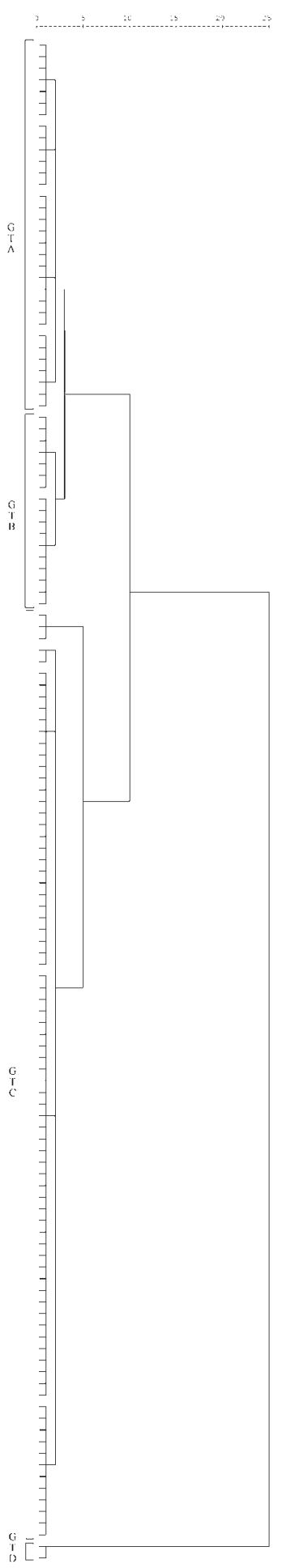

Fig. 1. Dendrograma realizado sobre 132 cerámicas mallorquinas fechadas entre el 1750 a.C. y el 50 a.C. Se considera el porcentaje y tamaño de antiplástico mineral (véase Fig. 2) y el porcentaje de materia vegetal utilizando distancia euclidiana al cuadrado y agrupamiento centroide. 
mos básicamente ante dos tipos de fábricas texturalmente diferenciadas. Se caracterizan de forma sintética los cuatro GT establecidos (Fig. 3):
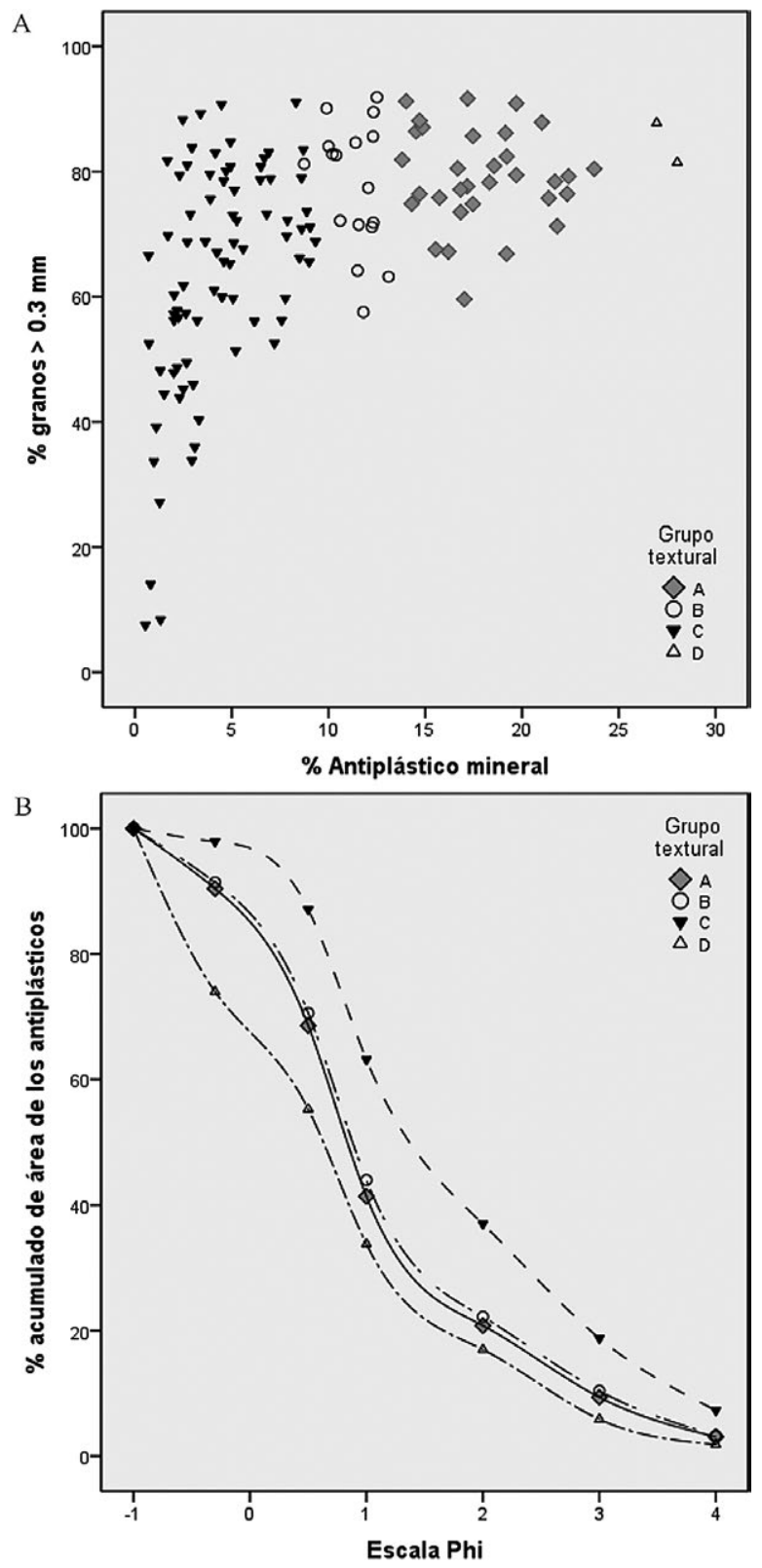

Fig. 2. Detalle de los atributos de los grupos texturales obtenidos en el dendrograma (Fig. 1). A. Gráfico de dispersión señalando su distribución en función del porcentaje de antiplástico mineral y el porcentaje de granos mayores de $0,3 \mathrm{~mm}$ presentes en la pasta. B. Curvas granulométricas acumulativas en función del porcentaje de área de cada intervalo de tamaño de grano ajustado a una escala Phi. a) Grupo Textural A (GT-A): consta de 32 piezas con cantidades altas de antiplásticos de origen mineral (14-22\%), principalmente de tamaño grueso-medio o medio $(>300 \mu \mathrm{m})$. El desgrasante vegetal suele ser nulo o residual: inferior al 5\% casi en todas ellas. Incluye cerámicas de cronología diversa, donde abundan las de los periodos de la Edad del Bronce Final, Talayótico y Postalayótico I. Las del Postalayótico II son meramente testimoniales.

b) Grupo Textural B (GT-B): constituido por 17 piezas con cantidades medias de desgrasante mineral $(8,5-13 \%)$, en general de tamaño grueso-medio o medio $(>300 \mu \mathrm{m})$. La cantidad de desgrasante vegetal varía mucho. Está ausente en algunas y en otras aparece en cantidades muy altas. Las segundas corresponden al periodo postalayótico, el mejor representado, aunque la composición cronológica es variada, habiendo algunas piezas del Bronce Final. La granulometría de las muestras permite establecer distintos subgrupos. El GT-B1 presenta un tamaño de grano grueso/medio $(86 \%>300 \mu \mathrm{m})$ con una distribución seriada de los granos y una cantidad media/alta de desgrasante vegetal $(5,8-12,2 \%)$. Los antiplásticos, en especial los de origen vegetal, están pobremente homogeneizados en la matriz. En el GT-B2 la fase mineral se ordena en una fracción media-fina $(85 \%<800 \mu \mathrm{m})$ según una distribución seriada. La cantidad de desgrasante orgánico es, como ya señalábamos, muy variable entre 1 y $18 \%$. En el GT-B se constata una variante secundaria formada por dos piezas del Bronce Final (CLG-1233; SM-475), una del Talayótico (TSF-1082) y una del Postalayótico II (TSF-57) sin este desgrasante.

c) Grupo Textural C (GT-C): engloba 80 piezas. Se opone claramente en el dendrograma a los GT-A y B. Estas cerámicas tienen cantidades medias (5-9\%) y en especial bajas de fase mineral $(<3 \%)$, siendo la granulometría principalmente de tamaño medio $(300-800 \mu \mathrm{m})$ y fino $(<300 \mu \mathrm{m})$. Faltan las texturas gruesas y la cantidad de desgrasante vegetal es extremadamente variable. En algunas piezas es residual o muy escaso $y$ en otras aparece en muy altas concentra- 

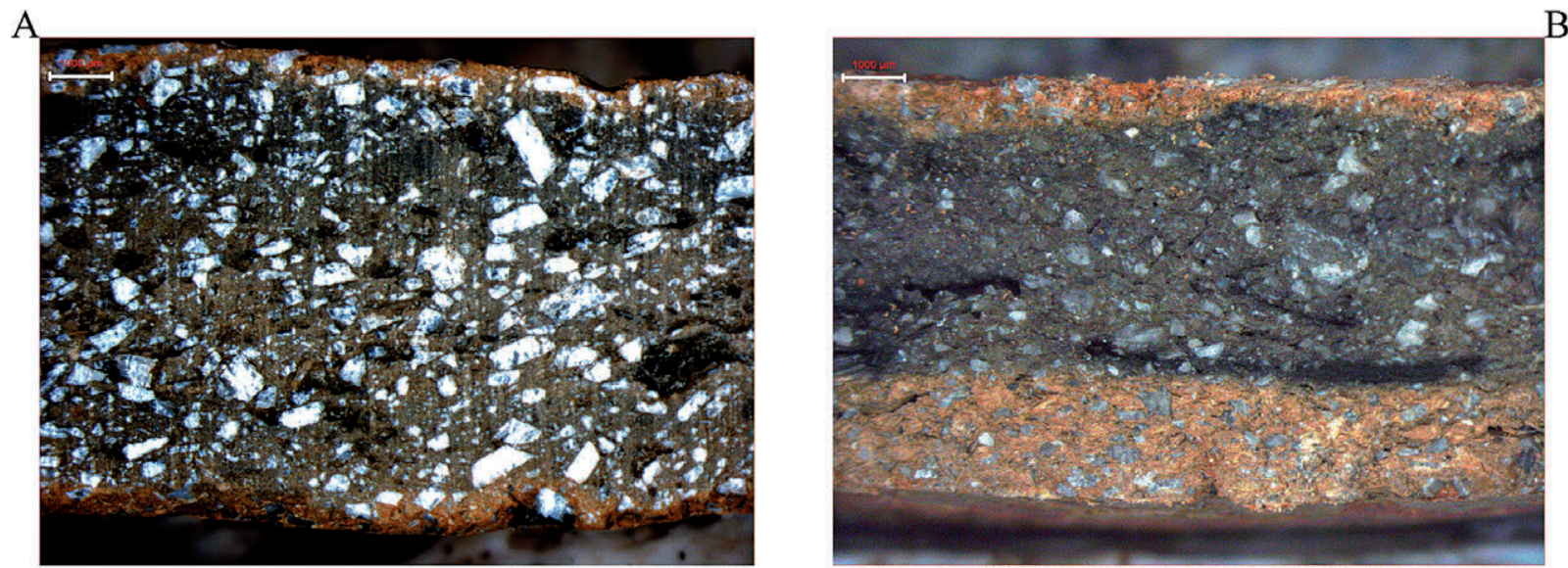

$\mathrm{C}$
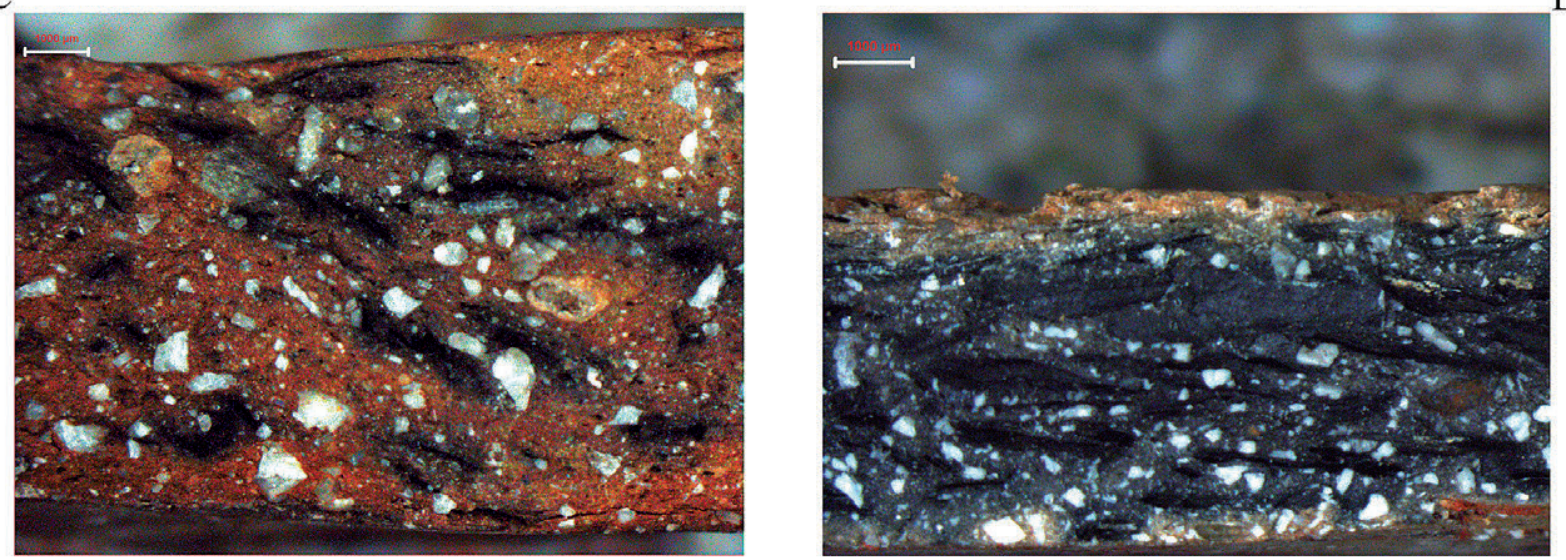

$\mathrm{E}$
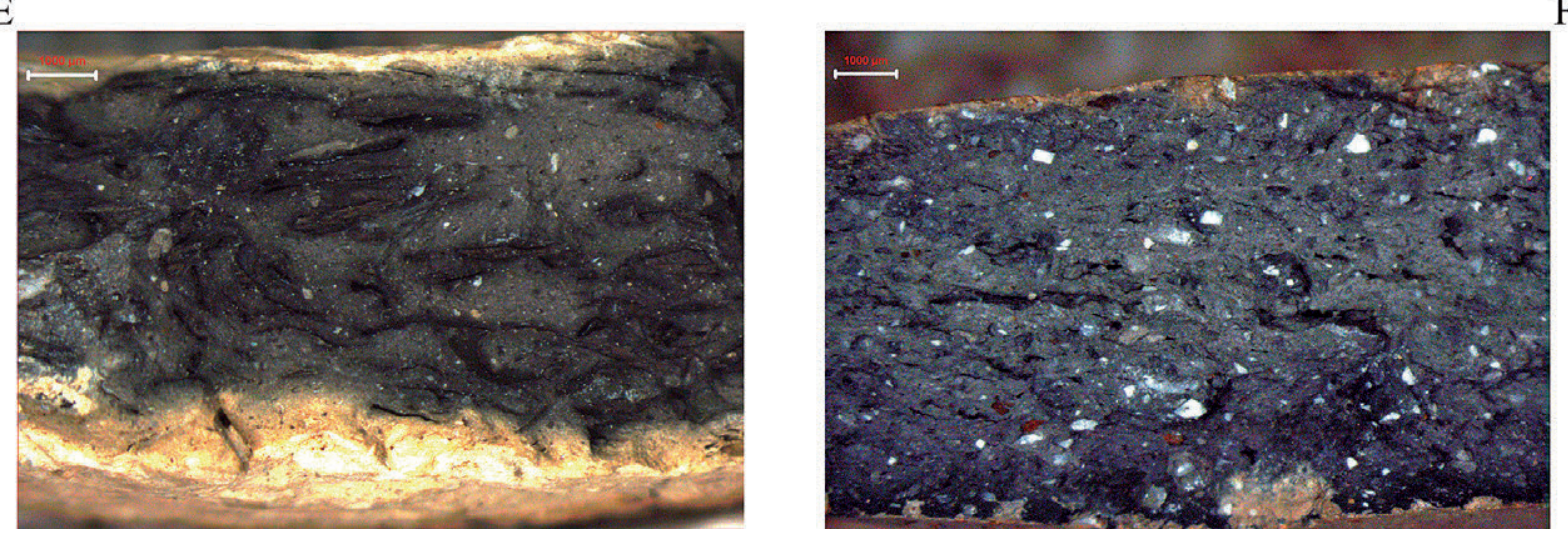

Fig. 3. Micrografías pertenecientes a tres de los grupos texturales (GT) establecidos en las 132 cerámicas mallorquinas (todas las escalas a $1 \mathrm{~mm}$ ). A. GT-A (SM-473); B. GT-A abundante mineral y algún poro aislado de materia orgánica (TSF-1117); C. GT-B (SM-697); D. GT-B2 cantidades medias de antiplástico mineral de tamaño medio (300-800 $\mu$ m) y altas de desgrasante vegetal (TSF-353). E. GT-C cantidades muy bajas de antiplástico mineral de tamaño fino $(<300$ $\mu \mathrm{m})$ y altas de desgrasante vegetal (TSF-1048). F. GT-C variante sin desgrasante vegetal adscrita al Bronce Antiguo (CLG-154). SM Torre I de Puig de Sa Morisca, TSF Son Ferrer, CLG Closos de Can Gaià. Publicada en color en la edición electrónica. 
ciones $(<21 \%)$. En este gran grupo están la mayoría de las cerámicas del Postalayótico I y II, así como las escasas piezas que se analizaron del Bronce Antiguo. Las del Bronce Final y Talayótico son muy minoritarias y se asocian al GT-C3 que tiene las texturas más gruesas del grupo. En el dendrograma se distinguen cuatro subgrupos definidos por la cantidad y el tamaño del antiplástico mineral. El GT-C1 engloba piezas con escasas inclusiones minerales $(<1,5 \%)$ muy bien ordenadas en su fracción más fina $(90 \%<300 \mu \mathrm{m})$ y una cantidad media/alta de materia vegetal (10-14,5\%). El GT-C2 se asemeja al anterior en la cantidad extremadamente baja de fase mineral $(<3,5 \%)$ que, sin embargo, se ordena en una fracción fina-media $(96 \%<800 \mu \mathrm{m})$. En las piezas del GT-C3 la cantidad de antiplástico mineral es baja-media (3,5-9,3\%) y ordenada según una distribución normal en una fracción media/fina $(86 \%<800 \mu \mathrm{m})$. La del desgrasante vegetal oscila mucho pero siempre por debajo del $12 \%$. En los ejemplares del GT-C4 la cantidad de fase mineral es baja $(<5 \%)$ y ordenada en una fracción media-gruesa $(80 \%>300 \mu \mathrm{m})$. Suelen ser muestras con textura fina, sin apenas antiplásticos de origen mineral y con una distribución bimodal, donde algún grano aislado supera las $500 \mu \mathrm{m}$.

d) Grupo Textural D (GT-D): comprende dos piezas de la Edad del Bronce Medio/Final, separadas de las de los demás grupos establecidos en el dendrograma por su textura con una cantidad muy alta de desgrasante mineral $(27-28 \%)$ de un tamaño grueso-medio $(83 \%>300 \mu \mathrm{m})$ y ordenado de forma seriada. Estas pastas no poseen desgrasante vegetal. Algunos de sus rasgos texturales están muy relacionados con los constatados en el GT-A.

Los cuatro GT evidencian diferentes elecciones tecnológicas de los alfarero/as en relación a las materias primas utilizadas en la producción y/o las estrategias seguidas en la preparación de las pastas. Como se ha comentado, algunos de estos grupos presentan abundantes antiplásticos de tamaño medio o grueso. Ambas variables, así como la esfericidad de los granos, se consideran indicadores de la adición de materia mineral a las pastas cerámicas (Albero 2014a). Para constatar este aspecto se ha calculado un índice que expresa la abundancia de desgrasante de tamaño medio o grueso en las piezas. Se ha formulado sumando los intervalos de tamaño $\left(I_{t}\right)$ referidos a granos de más de $260 \mu \mathrm{m}$ de longitud y dividiendo el valor obtenido por la cantidad de mineral registrado en la pasta. Las piezas con valores más bajos en el 'índice de tamaño y cantidad de desgrasante' ( $\left.\mathrm{I}_{\text {tc }}\right)$ serán las de texturas más gruesas y, por tanto, con más probabilidades de contener desgrasantes añadidos. El cálculo de este índice se resume en la siguiente ecuación: $I_{t c}=(I t 4+I t 5+I t 6+$ It 7$) / \%$ antiplástico mineral. Al aplicar este índice, la dispersión de los valores de $\mathrm{I}_{\text {tc }}$ en GT-A, B y D contrasta con la observada para GT-C. En este grupo es muy variable, pero notablemente más elevado que en los anteriores (Fig. 4), evidenciando que las probabilidades de tener abundantes desgrasantes añadidos intencionalmente son menores en las piezas de GT-C.

Considerando la dimensión tecnológica de las agrupaciones y las apreciaciones realizadas a partir del $I_{\text {tc }}$ vale la pena plantear si los tipos de pastas constatados se relacionan o no con la temporalidad. Un análisis diacrónico nos puede informar si las tradiciones tecnológicas y el uso de recetas de pastas variaron durante la Edad del Bronce y del Hierro. Las variables texturales por periodos indican el tipo de pasta que predomina en cada fase (Fig. 5A). Se completa con un

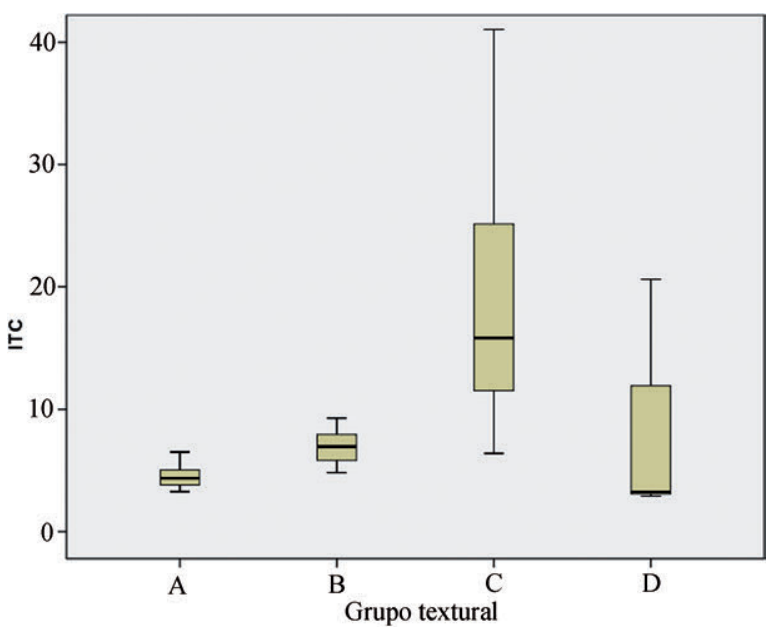

Fig. 4. Diagrama de cajas mostrando la distribución del 'índice de tamaño y cantidad' $\left(\mathrm{I}_{\mathrm{tc}}\right)$ de antiplástico mineral según el GT de las 132 cerámicas mallorquinas. 

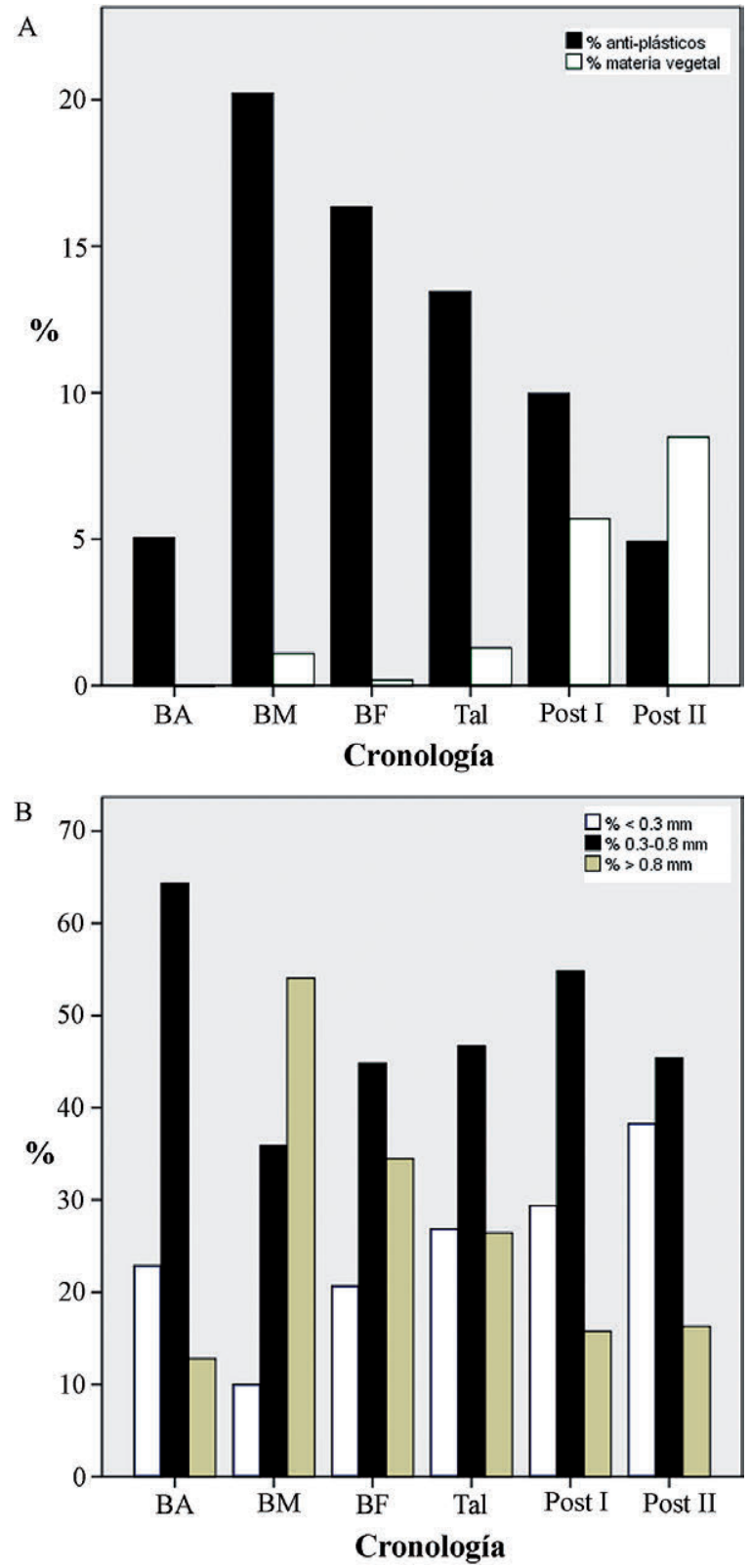

Fig. 5. Análisis diacrónico del tipo de pasta de las 132 cerámicas mallorquinas a partir de: A. las medias del porcentaje de antiplásticos minerales y vegetales; B. el porcentaje de granos de tamaño fino, medio y grueso. B Edad del Bronce, A Antiguo, M Medio, F Final, T Talayótico, Post Postalayótico.

diagrama de cajas expresivo de la dispersión en torno a la media del $\mathrm{I}_{\mathrm{tc}}$ en los distintos periodos (Fig. 6A). Ambos gráficos reflejan tendencias en la textura de las pastas en función de la cronología de las vasijas.
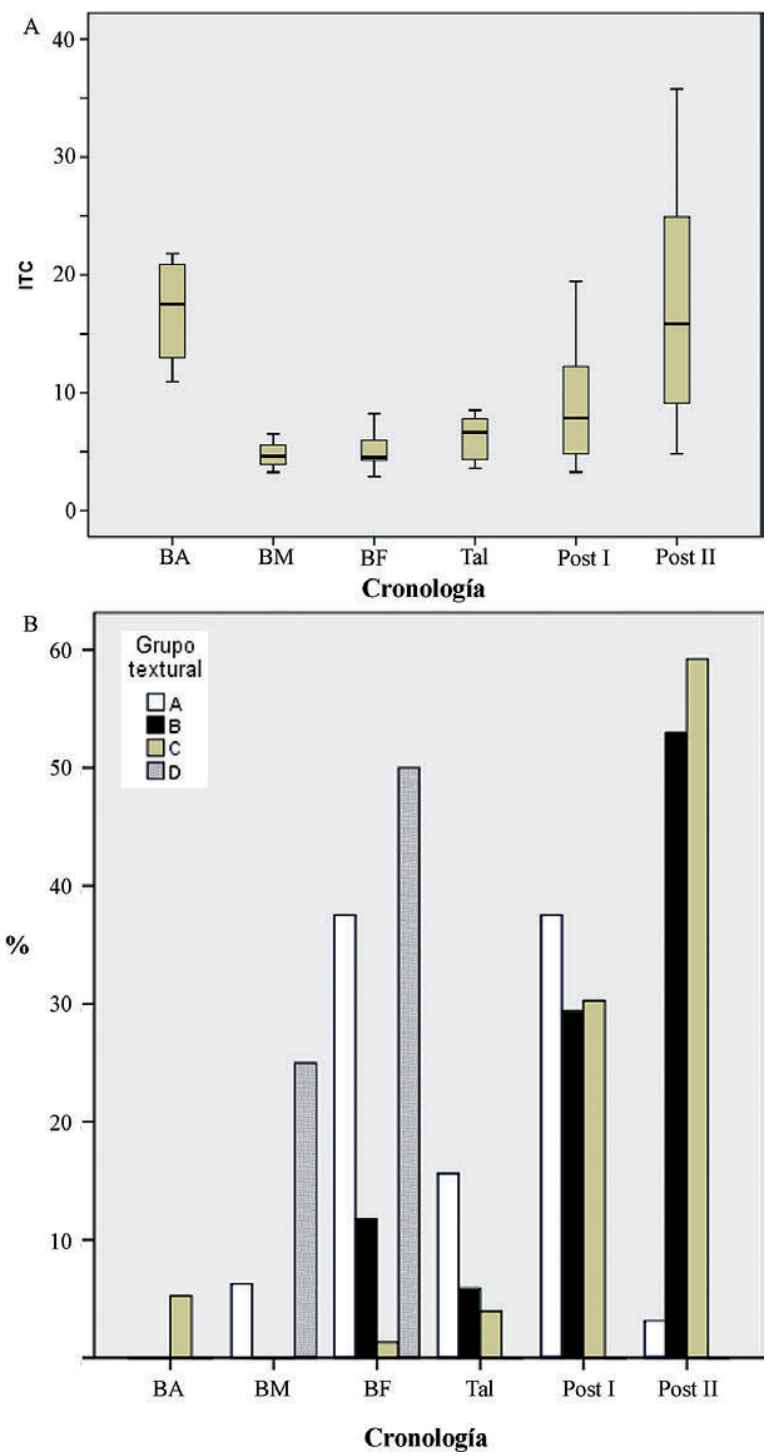

Fig. 6 Tendencias en la textura de las cerámicas mallorquinas en función de su cronología: A. Diagrama de cajas mostrando la distribución del índice de tamaño y cantidad ( $\mathrm{I}_{\text {tc }}$ ) de antiplástico mineral; B. Distribución por periodos del porcentaje de piezas de cada grupo textural. B Edad del Bronce, A Antiguo, M Medio, F Final, T Talayótico, Post Postalayótico.

Las cerámicas de la Edad del Bronce Antiguo muestran una clara ruptura con las del Bronce Medio. La textura de las primeras se asocia al GT-C, con escasos antiplásticos de origen mineral y vegetal. Abundan pastas de textura media con granos inferiores a $800 \mu \mathrm{m}$. Esta textura poco gruesa se materializa en un alto $I_{t c}$. Las 
piezas del Bronce Medio se asocian a pastas de los GT-A y D con un incremento notable del desgrasante mineral de tamaño grueso $(>800$ $\mu \mathrm{m}) \mathrm{y}$, por tanto, un bajo $\mathrm{I}_{\text {tc }}$. Si bien este cambio en las texturas resulta significativo, el escaso número de muestras analizadas de este periodo exige la confirmación futura de esta hipótesis. La tendencia observada en el Bronce Medio se mantiene durante el Bronce Final y la época talayótica, donde predominan pastas del GT-A con numeroso desgrasante mineral y un bajo $\mathrm{I}_{\mathrm{tc}}$. En estos periodos predomina un tamaño de grano más homogéneo, ordenándose progresivamente en una fracción preferentemente sub-milimétrica (Fig. 5B). En menor medida se detectan pastas tipo GT-B con texturas menos gruesas y, marginalmente, pastas tipo GT-C. La textura gruesa de la amplia mayoría de las cerámicas estudiadas de este periodo debe relacionarse con la generalización de una receta cerámica en las Islas Baleares consistente en la adición de importantes cantidades de calcita espática a las arcillas. Esta receta se ha consignado en múltiples yacimientos de Mallorca, Menorca e incluso Formentera a través de análisis petrológicos (Waldren 1982; GómezGras y Risch 1999; García Orellana et al. 2001; Risch y Gómez-Gras 2003; Andreu et al. 2007; Albero 2011; Albero 2014b; Albero et al. 2014).

Durante el Postalayótico se observa una progresiva disminución del porcentaje de antiplástico mineral y las pastas cada vez muestran más partículas de grano fino $(<300 \mu \mathrm{m})$. Ello se traduce en un incremento de la dispersión de los valores del $\mathrm{I}_{\mathrm{tc}}$, evidenciando un número mayor de individuos con $\mathrm{I}_{\mathrm{tc}}$ altos. Por un lado, en el Postalayótico I siguen teniendo especial importancia las piezas asociadas al GT-A, sin embargo hay un importante incremento de pastas tipo GT-B2 con una granulometría media. Diversos estudios petrológicos lo han relacionado con la continuidad en el uso de la receta basada en la adición de calcita espática en las cerámicas al menos hasta finales del siglo IV a.C., así como de otras rocas calcáreas o de chamota como desgrasante (Palomar 2005; A1bero 2011; Albero 2014b; Albero et al. 2014). Por otro lado, la cantidad de desgrasante vegetal se incrementa progresivamente a medida que avanzamos hacia el cambio de Era (Fig. 5A). Como indican varios autores, a partir del siglo
V a.C. las piezas que antes estaban desgrasadas sólo con calcita espática empiezan a incorporar desgrasante vegetal (Waldren 1982; Aramburu y Hernández 2005: 121; Palomar 2005; Albero 2011). Esta variación en la tradición insular se documenta exclusivamente en Mallorca, donde su uso es generalizado. La introducción de este desgrasante comportó cambios estructurales en los procesos de fabricación y uso de las vasijas. La adición de importantes cantidades de materia orgánica alteró las propiedades fisicoquímicas del material y su comportamiento durante el secado y la cocción (Albero 2010). Además debió afectar también a aspectos como la durabilidad o la funcionalidad potencial de las vasijas (Albero 2011). En esta fase empiezan a fabricarse también piezas con texturas finas asociadas al GT-C (Fig. 6B).

Finalmente, las piezas del Postalayótico II contienen más materia orgánica y una textura más fina con escaso desgrasante mineral. En muchas aparecen algunos granos aislados de tamaño grueso, a veces, en distribución bimodal. Las pastas tipo GT-A son muy marginales. La mayoría de las piezas fueron modeladas con pastas tipo GT-C, donde se observa además un grupo muy fino (GT$\mathrm{C} 1)$, exclusivo de este periodo. También existen bastantes piezas fabricadas con pastas tipo GT-B con un ligero incremento de la materia mineral de tamaño medio. El $\mathrm{I}_{\mathrm{tc}}$ es mucho más alto que en épocas anteriores, tanto en la media como en los valores máximos, lo que resulta indicativo del incremento de pastas con textura más fina en el registro. Este cambio en la textura de las cerámicas evidencia otras alteraciones importantes en las elecciones tecnológicas de los alfareros. Como se ha propuesto en otros trabajos (Aramburu y Hernández 2005; Albero 2011; Albero et al. 2014), parece ser que a partir del siglo III/II a.C. se abandonan los desgrasantes de naturaleza carbonatada. Esta tendencia general explica el predominio de pastas de textura fina. Sin embargo, en esta fase se aprecia también el uso de pastas con diversos tipos de texturas. Este hecho nos remite a la multiplicidad de soluciones tecnológicas y de estrategias de fabricación que caracteriza a toda la Edad del Hierro Final II y en especial al registro cerámico de los siglos III-I a.C. de Mallorca (Albero 2011; Albero et al. 2012; Albero et al. 2014; Albero y Weiss 2015; Albero et al. e. p.). 


\section{CONCLUSIONES}

En este artículo se ha valorado la importancia de los análisis texturales a la hora de caracterizar la cerámica y abordar diversos aspectos tecnológicos como la selección de la materia prima, la preparación de las pastas e incluso la aplicación de ciertos tratamientos de superficie como los engobes. Se han sintetizado los métodos y rutinas analíticas de uso habitual en la caracterización de la textura de las cerámicas desde los años 1980 hasta la actualidad recalcando el potencial de técnicas como el análisis de imágenes digitales. Se han expuesto los fundamentos básicos de este método, aplicándolo a un caso de estudio centrado en la prehistoria balear. Se ha calculado el porcentaje de antiplásticos de origen mineral y vegetal y se ha medido la longitud de los granos en 132 muestras cerámicas de la Edad del Bronce y del Hierro de diversos yacimientos de Mallorca.

El procedimiento empleado, combinado con análisis multivariantes, ha permitido clasificar el registro estudiado en una serie de grupos y subgrupos texturales con rasgos propios dependiendo de la cantidad y la granulometría de los antiplásticos. Un análisis diacrónico de los grupos texturales ha reconocido importantes cambios en las pastas producidos a lo largo de la prehistoria balear. Las pastas de la Edad del Bronce Antiguo han mostrado una textura fina, con escasos desgrasantes o inclusiones, carente de materia orgánica. En el Bronce Medio y durante el Bronce Final y Hierro Inicial (Talayótico) la situación cambia. Se desarrollan pastas de carácter grueso con abundantes desgrasantes de tamaño considerable con una ordenación polimodal que a lo largo de estos periodos tendrá tendencia a ser submilimétrica. Este tipo de texturas tendrá todavía un peso notable en el Hierro Final I (Postalayótico I), aunque la mayor presencia de piezas del GT-B revela un ligero descenso en la cantidad de antiplásticos minerales de las muestras. Así mismo, a diferencia de periodos anteriores, en este se generalizan texturas con importantes poros originados por la combustión de la materia orgánica contenida en las muestras y aparecen algunas piezas de textura fina adscritas al GT-C. En el Hierro Final II (Postalayótico II) casi de- saparecen las piezas de textura gruesa vinculadas al GT-A y se desarrollan pastas muy finas con escasas inclusiones minerales y cantidades más elevadas de materia orgánica.

Los cambios observados en la textura de las cerámicas han podido relacionarse, gracias a la información arqueométrica disponible, con la aparición y el abandono de determinadas recetas utilizadas para preparar las pastas en la producción de cerámica de las Islas Baleares y en concreto de Mallorca. Especialmente significativas son las elecciones tecnológicas de los alfareros consistentes en la adición de rocas calcáreas (sobre todo calcita espática) y de materia orgánica como desgrasante a las arcillas. De este modo, se ha detectado como la textura de las muestras nos informa de las tradiciones tecnológicas puestas en práctica por los alfareros. Este tipo de análisis favorece una aproximación multidimensional a la cerámica, en la que diversas metodologías nos proporcionan información de diversa índole complementaria entre sí.

\section{AGRADECIMIENTOS}

El trabajo es parte de la transferencia de conocimientos del proyecto de investigación $\mathrm{I}+\mathrm{D}$ "Archipiélagos: Paisajes, comunidades prehistóricas insulares y estrategias de conectividad en el Mediterráneo occidental. El caso de las Islas Baleares durante la Prehistoria" (HAR201567211-P) financiado por el Ministerio de Economía y Competitividad. Los análisis texturales con análisis de imagen se realizaron en el Laboratorio de Arqueometría Dr. A. Arribas del Dpto. de Prehistoria y Arqueología de la Universidad de Granada. Agradezco profundamente a la Dra. J. Capel y al Dr. F. Molina el haberme facilitado el acceso a dichas instalaciones, así como al instrumental necesario para desarrollar este trabajo. Los Dres. Manuel Calvo Trías y Jaume García Rosselló, así como el equipo director del "projecte Closos", pusieron a mi disposición las muestras cerámicas recuperadas en los yacimientos de Closos de Can Gaià y el Turriforme escalonado de Son Ferrer. 


\section{BIBLIOGRAFÍA}

Albero, D. 2010: "Pastas desgrasadas con calcita y pastas desgrasadas con materia vegetal: aproximación experimental". Boletín del Laboratorio de Petrología y Conservación Cerámica 2 (2): 18-34.

Albero, D. 2011: Caracterización tecnológica, social y adaptación funcional de cerámicas prehistóricas en el Oeste y Sureste de Mallorca (1700-50 BC): aproximación sincrónica y diacrónica a partir del estudio arqueométrico de pastas. Tesis, Universidad de Granada. http://hdl.handle.net/10481/18426 (consulta 28-VI-2016)

Albero, D. 2014a: Materiality, Techniques and Society in Pottery Production: The Technological Study of Archaeological Ceramics Through Paste Analysis. De Gruyter Open Ltd. Warsaw/Berlin.

Albero, D. 2014b: "Identifying spathic calcite recipe in archaeological ceramics: possibilities \& limitations". Cerâmica 60: 379-391.

Albero, D.; García, J. y Calvo, M. 2012: "La utilización de engobes en las comunidades postalayòticas de la zona de Santa Ponça (V-I a.C.)". Actas de las IV Jornadas de la Sección de Arqueología del Colegio de Doctores y Licenciados en Filosofía y Letras de las Islas Baleares (Ibiza 2010): 61-70. Palma de Mallorca.

Albero, D.; García, J. y Calvo, M. 2014: "Pottery Production in Santa Ponsa (Majorca, Spain) from the Late Bronze to the Late Iron Age (1100-50 BC): ceramics, technology and society". En M. Martinón-Torres (ed.): Craft and science: International perspectives on archaeological ceramics. University College London, Qatar Series in Archaeology and Cultural Heritage, Bloomsbury Qatar Foundation. Doha, Qatar: 73-84.

Albero, D. y Mateu, G. 2012: "Raw materials and pottery production at the Late Bronze and Iron Age Site of Puig de Sa Morisca (Mallorca, Spain)". Geoarchaeology 27 (4): 285-299.

Albero, D.; Vidal, A.; García, J. y Calvo, M. en prensa: "Communities of practice and potter's experience: a case study from southwestern Mallorca (c. 500-50 BC)". En J. Vukovic y I. Miloglav (eds.): Artisans rule: product standardization and craft specialization in Prehistoric Society. Cambridge Scholars Publishing. Cambridge.

Albero, D. y Weiss, D. 2015: "Análisis de elementos decorativos en cerámicas postalayóticas de Mallorca". Actas de las VI Jornadas de Arqueología de las Islas Baleares (Formentera 2014): 119-128. Formentera.

Andreu, G.; Badia, M.; Gómez-Gras, D.; Lull, V.; Micó, R.; Martín-Martín, J. D.; Palomar, B.; Rihuete, C. y Risch, R. 2007: "El desarrollo de la alfarería prehistórica en Menorca: una primera aproximación". L'arqueología a Menorca: eina per al coneixement del passat. Consell Insular de Menorca. Menorca: 125-141.
Aramburu, F. J. y Hernández, J. 2005: Memoria de las excavaciones arqueológicas en el poblado talayótico de Ses Païsses (Artà, Mallorca). Campañas 1999-2000. CD-ROM, Palma de Mallorca, www.Arqueobalear.com (consultada en abril de 2010).

Barceló, J. A.; Pijoan, J. y Oriol, V. 2001: "Image quantification as archaelogical description". En Z. Stancic y T. Veljanovsky: Computing Archaeology for Understanding the pastk. British Archaeological Reports, International Series 934, Archaeopress. Oxford: 69-78.

Barraclough, A. 1992: "Quaternary sediment analysis: a deductive approach at A-level". Teaching Geography 17: 15-18.

Betts, I. M. 1982: "Roman brick and tile: a study in fabric variability". En I. Freestone, C. Johns y T. Potter (eds.): Current research in ceramics: thinsection studies. British Museum Occasional Paper 32. Londres: 63-71.

Bronitsky, G. y Hamer, R. 1986: "Experiments in ceramic technology: the effects of various tempering materials on impact and thermal-shock resistance". American Antiquity 51 (1): 89- 101.

Buxeda, J.; Cau, M. A.; Sagrista, A. y Tuset, F. 1991: "Appréciation macroscopique et détermination des fabriques". Congrès Société Française d $>$ Etude de la Céramique Antique en Gaule (Cognac 1991): 425430. Marsella.

Calvo, M.; García, J.; Javaloyas, D.; Albero, D. y Van Strydonck, M. 2014: "Matching data: analysing the chronological use sequence in the Iron Age necropolis of the staggered turriform of Son Ferrer (Balearic Islands, Spain)". Radiocarbon 56 (2): 361-374.

Camps, J. y Vallespir, A. 1998: El Turó de les Abelles. Col-lecció La Deixa 1, Monografíes de Patrimoni Històric, Consell de Mallorca. Palma de Mallorca.

Capel, J. 1986: "Estudio mineralógico y geoquímico de sedimentos y cerámicas arqueológicas de algunos yacimientos de la Mancha". Oretum 2: 53-153.

Carpenito, G.; Corradini, L. y Levi, S. T. 2009: "Impasto 'fine, semifine o grossolano'? Terminologia archeologica e classificazione archeometrica". Le classi ceramiche: situazione degli studi. Atti della $10^{\circ}$ Giornata di Archeometria della Ceramica (Roma 2006): 33-45. Roma

Cuomo Di Caprio, N. 1985: La ceramica in archeologia: Antiche tecniche di lavorazione e moderni metodi d'indagine. Collana di Scienze dell'antichità, La Fenice. Roma.

Dal Sasso, G.; Maritan, L.; Salvatori, S.; Mazzoli, C. y Artoli, G. 2014: "Discriminating pottery production by image analysis: a case study of Mesolithic and Neolithic pottery from Al Khiday (Khartoum, Sudan)". Journal of Archaeological Science 46: 125-143.

Darvill, T. y Timby, J. 1982: "Textural analysis: a review of potentials and limitations". En I. Freestone, C. Johns y T. Potter (eds.): Current research 
in ceramics: thin-section studies. British Museum Occasional Paper 32. Londres: 73-84.

Echallier, J. C. 1984 : Éléments de technologie céramique et d'analyse des terres cuites archéologiques. Documents d'Archéologie Méridionale: Méthodes et Techniques 3. Lambesc.

Fieller, N. R. 1991: "Grain size analysis of archaeological pottery: the use of statistical models". En A. Middleton y I. Freestone (eds.): Recent developments in ceramic petrology. British Museum Occasional Paper 81. Londres: 71-111.

Frahm, E.; Nikolaidou, M. y Kelly-Buccellati, M. 2008: "Using Image Analysis Software to Correlate Sherd Scans in the Field and X-Ray Element Maps in the Laboratory". Society for Archaeological Sciences Bulletin 31 (2): 8-12.

Gallart, M. D. y Mata, M. P. 1999: “El análisis mineralógico y textural de dos cerámicas características del Neolítico, procedentes de La Rioja”. En J. Capel (ed.): Arqueometría y Arqueología. Monográfica Arte y Arqueología, Universidad de Granada. Granada: 57-68.

García del Amo, D. 2000: “Determinación de parámetros mineralógicos mediante análisis digital de imagen". Cadernos del Laboratorio Xeolóxico de Laxe 25: 119-122.

García Orellana, J.; Molera, J. y Vendrell, M. 2001: Caracterització de ceràmiques prehistòriques de l'illa de Menorca. Treballs del Museu de Menorca, Govern de les Illes Balears. Mahón.

Gherdán, K. y Horváth, T. 2009: "Petrographic investigation of the finds of Balatonószöd- Temetói Dülő Baden settlement”. En K. Biró, V. Szilágyi y A. Kreiter (eds.): Vessels: inside and outside Proceedings of the 9th European Meeting on ancient ceramics (Budapest 2007): 265-275. Budapest.

Gibson, A. y Woods, A. 1990: Prehistoric pottery for the archaeologist. Leicester University Press. Leicester.

Gómez-Gras, D. y Risch, R. 1999: "Análisis petrográficos de cerámicas de la Cova des Càrritx". En V. Lull, R. Micó, R. Risch y C. Rihuete (eds.): La Cova des Càrritx y la Cova des Mussol. Ideología y Sociedad en la Prehistoria de de Menorca. Consell Insular de Menorca. Mahón: 567-580.

Gose, E.; Johnsonbaugh, R. y Jost, S. 1996: Pattern recognition and Image analysis. Prentice Hall. Upper Sadler River, NJ.

Guerrero, V.; Calvo, M. y Salvà, B. 2002: “La cultura Talayótica: una sociedad de la Edad del Hierro en la periferia de la colonización fenicia". Complutum 13: 221-25.

Hamilton, S. 1977: "Excavations at Bishopstone". Sussex Archaeological Collections 115: 83-118.

Javaloyas, D.; Fornés, J. y Salvà, B. 2007: "Breve aproximación al conocimiento del yacimiento de Closos de Can Gaià”. En V. Guerrero, M. Calvo, J. García y S. Gornés (eds.): Prehistoria de las Islas
Baleares: Registro arqueológico y evolución social antes de la Edad del Hierro. British Archaeological Reports, Internacional Series 1690, Archaeopress. Oxford: 352-360.

Kilmurry, K. 1982: "The manufacture of Stamford ware: an application of thin-sectioning and neutron activation analysis". En I. Freestone, C. Johns y T. Potter (eds.): Current research in ceramics: Thinsection studies. British Museum Occasional Paper 32. Londres: 105- 111.

Livingood, P. y Cordell, A. 2009: "Point/counter point: the accuracy and feasibility of digital image techniques in the analysis of ceramic thin sections". Journal of Archaeological Science 36: 867-872.

Maggetti, M. 1982: "Phase analysis and its significance for technology and origin". En J. Olin (ed.): Archaeological Ceramics. Smithsonian Institution Press. Boston: 121-133.

Matthew, A. J.; Woods, A. J. y Oliver, C. 1991: "Spots before the eyes: new comparison of charts for visual percentage estimation in archaeological material". En A. Middleton y I. Freestone: Recent developments in ceramic petrology. British Museum Occasional Paper 81. Londres: 211-264.

Middleton, A.; Freestone, I. y Leese, M. 1985: “Textural analysis of ceramic thin sections: evaluation of grain sampling procedures". Archaeometry 27: 64-74.

Middleton, A.; Lesse, M. y Cowell, M. 1991: "Computer-assisted to the grouping of ceramics fabrics". En A. Middleton y I. Freestone (eds.): Recent developments in ceramic petrology. British Museum Occasional Paper 81. Londres: 265-275.

Olaetxea, C. 2000: "La tecnología cerámica en la protohistoria vasca". Munibe (Antropologia-Arkeologia) Suplemento 12: 11-211.

Orton, C.; Tyers, P. y Vince, A. 1993: La cerámica en arqueología. Crítica. Barcelona.

Palomar, B. 2005: La ceràmica posttalaiòtica de $\mathrm{Ma-}$ llorca. Significació económica i social dels canvis en el procés productiu entre c. 450-250 cal ANE: el cas de Son Fornés, Montü̈ri (Mallorca). Tesis doctoral, Universitat Autónoma de Barcelona, Bellaterra. Barcelona. http://ddd.uab.cat/record/38306 (consulta 29-VI-2016).

Polvorinos, A. 2001: “Contribución de la granulometría del desgrasante a la clasificación de texturas cerámicas arqueológicas". En B. Gómez, M. A. Respaldiza y M. ${ }^{\mathrm{a}} \mathrm{L}$. Pardo (eds.): III Congreso Nacional de Arqueometría (Sevilla 1999): 349-358. Sevilla.

Polvorinos, A.; Flores, V.; Tabales, M. A. y Hernández, M. J. 2003: “Caracterización y tecnología de materiales cerámicos romanos de los ss. I a III D.C procedentes del Hospital de las Cinco Llagas de Sevilla”. Boletín de la Sociedad Española de Cerámica y Vidrio 42 (2): 93-99.

Polvorinos, A.; García, L.; Hurtado, V. y Hernández, M. J. 2005: "Bronze Age ceramics in Southwest

Trab. Prehist., 73, N. ${ }^{\circ}$ 2, julio-diciembre 2016, pp. 251-267, ISSN: 0082-5638

doi: $10.3989 /$ tp.2016.12172 
Spain: an exploratory archaeometric study of technology and function". Geoarchaeology 20 (3): 263-284.

Polvorinos, A.; Hurtado, V.; Hernández, M. J. y Almarza, J. 2002: "Arqueometría de cerámicas de la tumba 3 del yacimiento calcolítico de La Pijotilla (Badajoz)". IV Congreso Nacional de Arqueometría (Valencia 2001): 315-321. Valencia.

Quinn, P. 2013: Ceramic petrography: the interpretation of archaeological pottery \& related artefacts in thin section. Archaeopress. Oxford.

Reedy, C. L. 2006: "Review of digital image analysis of petrographic thin sections in conservation research". Journal of the American Institute for Conservation 45: 127-146.

Reedy, C. L. 2008: Thin-Section Petrography of Stone and Ceramic Cultural Materials. Archetype Publications Ltd. London.

Reedy, C. L.; Anderson, J.; Reedy, T. y Liu, Y. 2014: "Image analysis in quantitative particle studies of archaeological ceramic thin sections". Advances in Archaeological Practice 2 (4): 252-268.

Rice, P. M. 1987: Pottery analysis: A Sourcebook. The University of Chicago Press. Chicago.

Risch, R. y Gómez-Gras, D. 2003: "La producción alfarera en época talayótica. Estudio petrográfico y paleotecnológico de los materiales de Son Ferragut (Sineu, Mallorca)". En P. Castro, T. Escoriza y M. E. Sanahuja (eds.): Mujeres y hombres en espacios domésticos: trabajo y vida social en la Prehistoria de Mallorca (c. 700-500 cal ANE). British Archaeological Reports internacional Series, Archaeopress. Oxford: 190-216.

Sestier, C.; Martineau, R.; Chenu, E.; Elias, A.; Goydadin, R. y Ladmira, E. 2003: "Imaging vegetal inclusions in porous clayey materials and ceramics, by impregnation with fluorescent polymers". Understanding people through their pottery: 251-261.

Skibo, J. M. y Schiffer, M. B. 1987: "The effects of water on processes of ceramic abrasion". Journal of Archaeological Science 14: 83-96.

Sobott, R.; Bente, K. y Kittel, M. 2014: "Comparative porosity measurements on ceramic materials". The old potters almanack 19 (1): 18-25.
Soltman, J. 2001: "The role of petrography in the study of archaeological ceramics". En P. Goldberg, V. Holliday y C. Ferring (eds.): Earth Sciences and Archeology. Kluwer Academic/Plenum Press. New York: 297-326.

Sonka, M.; Hlavac, V. y Boyle, R. 1994: Image processing: Analysis and Machine Vision. Chapman and Hall. London.

Steponaitis, V. P. 1984: "Technological studies of prehistoric pottery of Alabama: physical properties and vessel function". En S. Van der Leeuw y A. C. Pritchard (eds.): The many dimensions of pottery: ceramics in archaeology and anthropology. Universiteit, Albert Egges van Giffen Instituut voor Praeen Protohistorie. Amsterdam: 79-122.

Streeten, A. 1982: "Textural analysis: an approach to the characterization of sand-tempered ceramics". En I. Freestone, C. Johns y T. Potter (eds.): Current research in ceramics: thin-section studies. British Museum Occasional Paper 32. Londres: 123-134.

Tucker, M. 1991: Sedimentary Petrology: an introduction to the origin of sedimentary rocks. Blackwell Scientific Publications. Texas.

Velde, B. 2005: "Use of image analysis in determining multi-source ceramic materials". En A. LivingstoneSmith, D. Bosquet y R. Martineau (eds.): Pottery Manufacturing Processes: Reconstitution and Interpretation. British Archaeological Reports International Series 1349, Archaeopress. Oxford: 95-99.

Velde, B. y Druc, I. 1999: Archaeological ceramic materials: origin and utilization. Springer. Berlin.

Waldren, W. H. 1982: Balearic Prehistory Ecolgy and Culture: The excavation and study of certain Caves, Rocks Shelters and Settlements. British Archaeological Reports, International Series 149(i), Archaeopress. Oxford.

Whitbread, I. 1991: "Image and data processing in ceramic petrology". En A. Middleton y I. Freestone (eds.): Recent developments in ceramic petrology. British Museum Occasional Paper 81. Londres: 369-388.

Zähle, M. 1990: "Wicksell's Corpuscle Problem in Spherical Spaces". Journal of Applied Probability 27 (3): 701-706. 